\title{
Digital Library of Expert System Based at Indonesia Technology University
}

\author{
Dewa Gede Hendra Divayana ${ }^{1}$ \\ Chair of Information Technology Department \\ Indonesia Technology University \\ Bali, Indonesia
}

\author{
I Putu Wisna Ariawan ${ }^{2}$ \\ Lecture of Mathematics Education \\ Ganesha University of Education \\ Bali, Indonesia
}

\author{
I Made Sugiarta ${ }^{3}$ \\ Lecture of Mathematics Education \\ Ganesha University of Education \\ Bali, Indonesia
}

\author{
I Wayan Artanayasa ${ }^{4}$ \\ Chair of Sport \& Health Education Department \\ Ganesha University of Education \\ Bali, Indonesia
}

\begin{abstract}
Digital library is a very interesting phenomenon in the world of libraries. In this era of globalization, the digital library is needed by students, faculty, and the community in the search for quick reference through internet access, so that students, faculty, and the community does not have to come directly to the library. Accessing collections of digital libraries can also be done anytime and anywhere. Digital Library development also occurred at Indonesia Technology University. That University offers a digital library based of expert system. The concept of digital library is utilizing science expert system in the process of cataloging and searching digital collections. By using this digital library based of expert system, users can search the collection, reading collection, and download the desired collection by online system. The digital library based of expert system at Indonesia Technology University is built using the PHP programming language, MySQL database as a data base management system, and developed the method of forward chaining and backward chaining as inference engine.
\end{abstract}

Keywords-Digital Library; Expert System; Forward Chaining; Backward Chaining

\section{INTRODUCTION}

In the current era of globalization, information technology has a very important role in supporting the activities carried out by the community. The development of information technology very rapidly leads us toward the use of documents in digital form.

Library as one of the sources of knowledge needs to be organized and presented for the system services can be accessed from anywhere and anytime with the involvement of information technology in the form of an integrated system, so the user does not have to come directly to the library. This phenomenon is supported by the use of the Internet that facilitate processing, dissemination, and accessing information in digital form from anywhere and anytime. The development of increasingly sophisticated technology also affects the formation of a library in a digital form.

Digital library is a very interesting phenomenon in the world of libraries. In this era of globalization, the digital library is needed by students, faculty, and the community in the search for quick reference through internet access, so that students, faculty, and the community do not have to come directly to the library. Accessing collections of digital libraries can also be done anytime and anywhere. Digital Library development also occurred at Indonesia Technology University. That University offers a digital library based of expert system. The concept of digital library is utilizing science expert system in the process of cataloging and searching digital collections. By using this digital library based of expert system, users can search the collection, reading collection, and download the desired collection by online system.

\section{LITERATURE REVIEW}

\section{A. Digital Library}

In [1], The library has become digital: processes such as mass digitization, web archiving, and to a smaller extent digital preservation, are no longer isolated but disseminated among relevant production teams within the library.

In [2], A digital library (DL) is a library in which collections are stored in digital formats (as opposed to print, microform, or other media) and accessible by computers.

In [3], A digital library is a particular kind of information system which consists of a set of components, typically a collection (or collections) of computer system offering diverse services on a technical infrastructure, people, and the environment or usage.

In [4], Digital libraries are set of library activities and services which facilitate by electronic means the processing, transmission and display of information.

\section{B. Expert System}

In [5], an expert system is a computer program designed to simulate the problem-solving behaviour of a human who is an expert in a narrow domain or discipline. An expert system is normally composed of a knowledge base (information, heuristics, etc.), inference engine (analyses the knowledge base), and the end user interface (accepting inputs, generating outputs). The concepts for expert system 
development come from the subject domain of artificial intelligence $(\mathrm{AI})$, and require a departure from conventional computing practices and programming techniques.

In [6], an Expert system is software that simulates the performance of human experts in a specific field. Today's expert systems have been used in many areas where require decision making or predicting with expertise.

In [7], an expert system is a set of programs that manipulate encoded knowledge to solve problems in a specialized domain that normally requires human expertise.

In [8], Expert System is a branch of Artificial Intelligence that makes extensive use of specialized knowledge to solve problems at the human expert level.

In [9], the Expert System (ES) is one of the well-known reasoning techniques that is utilized in diagnosis applications domain. In ES, human knowledge about a particular expertise to accomplish a particular task is represented as facts and rules in its knowledge base.

In [10], an expert system is the computer system that emulates the behaviour of human experts in a wellspecified manner, and narrowly defines the domain of knowledge. It captures the knowledge and heuristics that an expert employs in a specific task. An overview of current technologies applied with an expert system that is developed for Database Management System, Decision Support System, and the other Intelligent Systems such as Neural Networks System, Genetic Algorithm, etc.

In [11], expert system is an artificial intelligence system that combines knowledge base with inference engine so that it can adopt the ability of the experts into a computer, so the computer can solve problems such as the often performed by experts.

\section{Forward Chaining}

The inference engine contains the methodology used to perform reasoning on the information in the knowledge base and used to formulate conclusions. Inference engine is the part that contains the mechanism and function of thought patterns of reasoning systems that are used by an expert. The mechanism will analyze a specific problem and will seek answers, conclusions or decisions are best. Because the inference engine is the most important part of an expert system, that plays a role in determining the effectiveness and efficiency of the system.

There are several ways that can be done in performing inference, including the Forward Chaining. In [12], an inference engine using forward chaining searches the inference rules until it finds one where the IF clause is known to be true.

When found it can conclude, or infer, the THEN clause, resulting in the addition of new information to its dataset. In other words, it starts with some facts and applies rules to find all possible conclusions. Therefore, it is also known as Data Driven Approach.

In [13], forward chaining is matching facts or statements starting from the left (first IF).

\section{Backward Chaining}

Also in [13], backward chaining is matching facts or statements starting from the right (first THEN). In other words, the reasoning starts from the first hypothesis, and to test the truth of this hypothesis to look for the facts that exist in the knowledge base.

In [14], an inference engine using backward chaining would search the inference rules until it finds one which has a THEN clause that matches a desired goal. If the IF clause of that inference rule is not known to be true, then it is added to the list of goals (in order for goal to be confirmed it must also provide data that confirms this new rule). In other words, this approach starts with the desired conclusion and works backward to find supporting facts. Therefore, it is also known as Goal-Driven Approach.

In [15], backward chaining systems are good for diagnostic and classification tasks, but they are not good for planning, design, process monitoring, and quite a few other tasks. In backward chaining, the search is goal directed, so rules can be applied that are necessary to achieve the goal.

\section{E. Digital Library Based of Expert System}

In [16], Digital Library Based of Expert System is a digital library that implements the basic concept of expert system includes a knowledge base and the inference engine in helping service mechanism. The knowledge base is used for storage and cataloging process of making collections that exist in digital library, while the inference engine is used to search the detail collection that available in digital libraries such as the ability to work like an expert.

\section{Methodology}

A. Object dan Research Site

1) Research Object is Digital Library Based of Expert System

2) Research Site at Indonesia Technology University.

\section{B. Data Type}

In this research, the authors use primary data, secondary data, quantitative data and qualitative data.

\section{Data Collection Techniques}

In this research, the authors use data collection techniques such as interviews, observation, and documentation.

\section{Analysis Techniques}

Analysis techniques used in this research is descriptive statistical.

\section{RESULT AND DISCUSSION}

A. Result

1) Early Trial

At this early trial, the authors conducted a limited scale testing of the digital library based of expert system that have been made previously by involving five staff at Indonesia Technology University to perform white box and black box testing. This test can be done by giving 10 questionnaires 
early trials digital library based of expert system to staff at Indonesia Technology University.

Diagram form of answers score percentage given by the respondents in early trial can be described as follows:

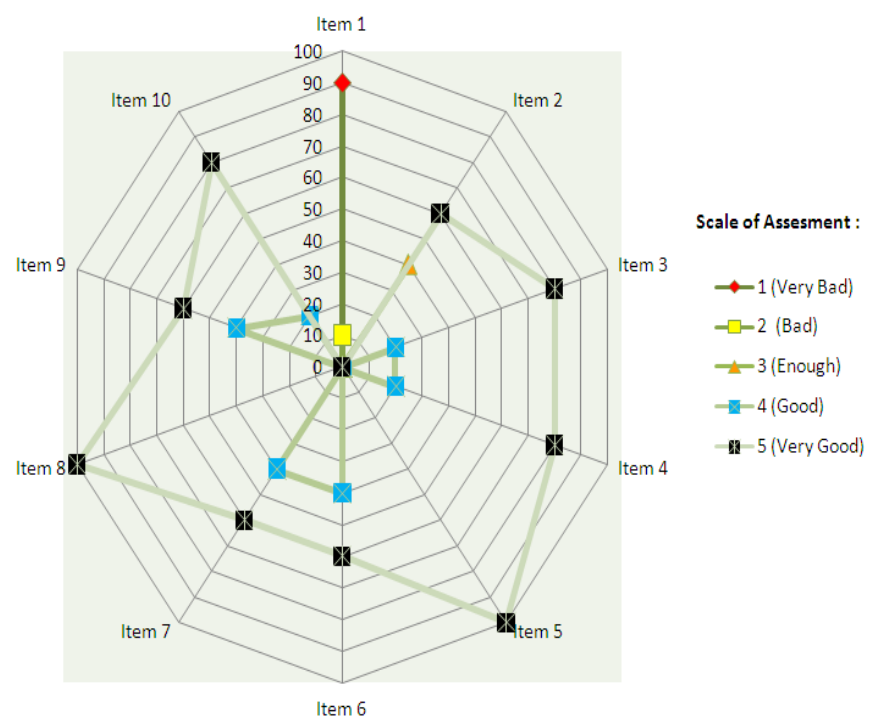

Fig. 1. Percentage Diagram of Respondents Answer Score In Early Trial

Based on the diagram above, it can be seen that the results of early trials of the digital library based of expert system, find a constraint that is the answer to a very bad score by $90 \%$ of the questions on the questionnaire $1^{\text {st }}$ initial trials. This is due to the unavailability of the form for the create of a new username and password for administrator in the future if there is a mutation of the staff who operate the digital library based of expert system. Given these constraints, then the system needs to be revised again.

\section{2) Field Trial}

At this field trial, the authors tested in a larger scale, involving an expert is understood about the digital library and ten staff at Indonesia Technology University. This test can be done by giving 15 questionnaires field trials for digital library based of expert system to the librarian and staff at Indonesia Technology University.

Diagram form of answers score percentage given by the respondents in field trial can be described as follows:

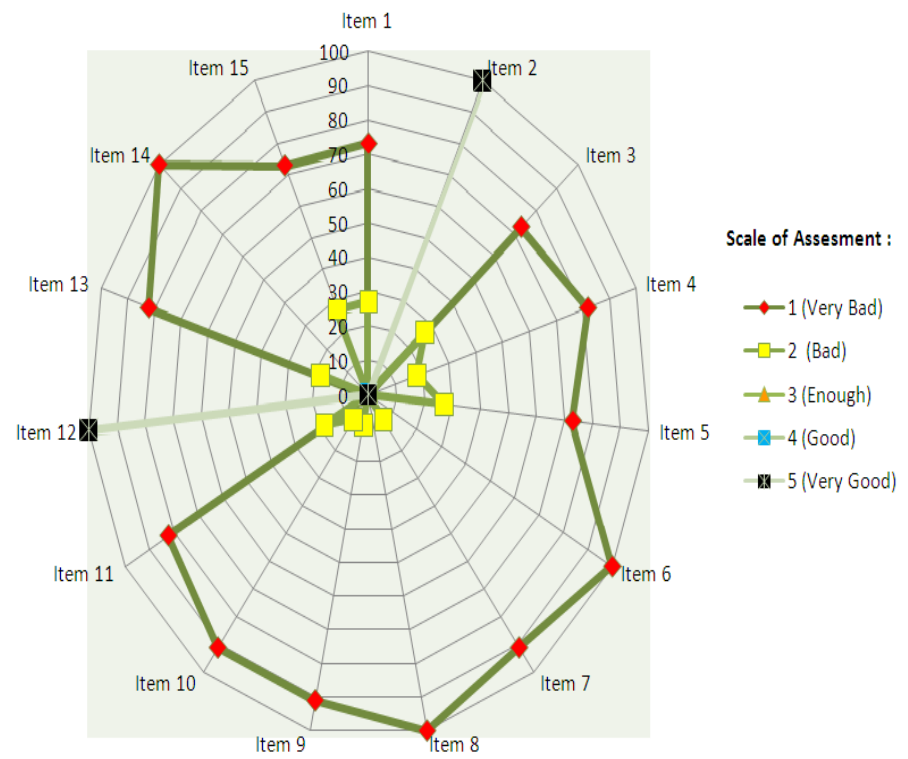

Fig. 2. Percentage Diagram of Respondents Answer Score In Field Trial

Based on the diagram above, it can be seen that the results of a field trial of the digital library based of expert system, the presence of obstacles that scores are very bad answer the score of $73 \%$ to the question $1^{\text {st }}, 3^{\text {rd }}, 5^{\text {th }}$, and $15^{\text {th }}, 82 \%$ of the questions $4^{\text {th }}, 11^{\text {th }}$ and $13^{\text {th }}$, at $91 \%$ of the questions $7^{\text {th }}, 9^{\text {th }}$, $10^{\text {th }}$, and at $100 \%$ of the questions $6^{\text {th }}, 8^{\text {th }}$ and $14^{\text {th }}$ on field trial questionnaire.

This is due to the unavailability of the collection input or edits form if in the future there is a new journal and article. Of the constraints are found, then the system needs to be revised to obtain collection more interactive and dynamic.

\section{3) Usage Test}

At this usage test, the authors conducted a trial involving with the use of 50 people (users). The test is performed to test the operation of the overall form available on digital library based of expert system that has undergone revisions to field trials. This test can be done by giving the user satisfaction questionnaire to users who visited Indonesia Technology University.

Diagram form of answers score percentage given by the respondents in usage test can be described as follows: 


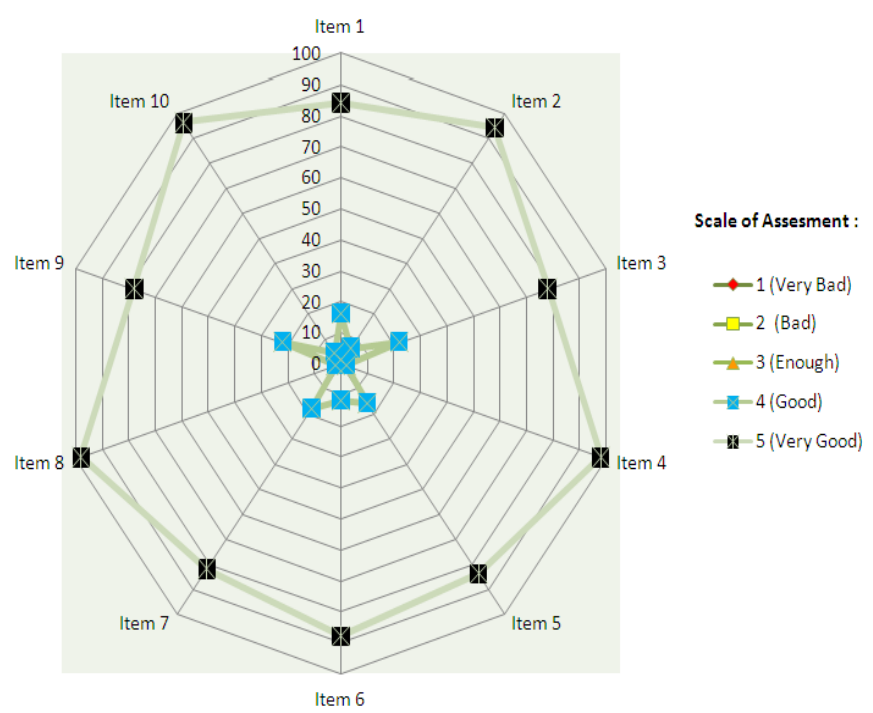

Fig. 3. Percentage Diagram of Respondents Answer Score In Usage Test

Based on the diagram above, it can be seen that the results of testing the use of the digital library based of expert system outline already looks very good and not found again the constraints in terms of technical operation (inputing and editing a new collection) as well as the principle method of expertise (forward chaining and bacward chaining method). This is evidenced by the percentage scoring very good response by $78 \%$ of questions $3^{\text {rd }}$, and $9^{\text {th }}$. Percentage scoring very good response by $82 \%$ of questions $7^{\text {th }}$. Percentage scoring very good response by $84 \%$ of questions $1^{\text {st }}$ and $5^{\text {th }}$. Percentage scoring very good response by $88 \%$ of statement $6^{\text {th }}$. Percentage scoring very good response by $94 \%$ of question $2^{\text {nd }}$. Percentage scoring very good response by $96 \%$ of questions $10^{\text {th }}$.

As well as scoring $98 \%$ of the questions $4^{\text {th }}$ and $8^{\text {th }}$ trial usage. And it would be even better if the digital library based of expert system added help fasility form for written in accordance with the suggestions of the respondents to the improvement of the system, so as to explain the performance of the expert system and the function of the buttons in the design of digital library based of expert system overall with easy to understand and simple language.

\section{B. Discussion}

1) Knowledge Base

Knowledge base is used to build the expert system obtained from multiple sources of knowledge, containing data on digital library based of expert system at Indonesia Technology University. The knowledge base contained in a digital library based of expert system at Indonesia Technology University can be described by the following table.
TABLE I. KNOWLEDGE BASE ON DIGITAL LIBRARY BASED OF EXPERT SYSTEM AT INDONESIA TECHNOLOGY UNIVERSITY

\begin{tabular}{|l|l|l|l|l|l|}
\hline No & Properties/Identity & Journal & Book & Magazine & Article \\
\hline 1. & Collection Code & $\sqrt{ }$ & $\sqrt{ }$ & $\sqrt{ }$ & $\sqrt{ }$ \\
\hline 2. & Collection Name & $\sqrt{ }$ & $\sqrt{ }$ & $\sqrt{ }$ & $\sqrt{ }$ \\
\hline 3. & Author & $\sqrt{ }$ & $\sqrt{ }$ & $\sqrt{ }$ & $\sqrt{ }$ \\
\hline 4. & Publisher & $\sqrt{ }$ & $\sqrt{ }$ & $\sqrt{ }$ & $\sqrt{ }$ \\
\hline 5. & Year of Issue & $\sqrt{ }$ & $\sqrt{ }$ & $\sqrt{ }$ & $\sqrt{ }$ \\
\hline 6. & Pages & $\sqrt{ }$ & $\sqrt{ }$ & $\sqrt{ }$ & $\sqrt{ }$ \\
\hline 7. & Place of Issue & $\sqrt{ }$ & $\sqrt{ }$ & $\sqrt{ }$ & $\sqrt{ }$ \\
\hline 8. & ISSN & $\sqrt{ }$ & $\sqrt{ }$ & $\sqrt{ }$ & $\sqrt{ }$ \\
\hline
\end{tabular}

2) Shows forward chaining concept in digital library based of expert system

Application of forward chaining method in a digital library can be explained by the following chart:

For example : search by collection code

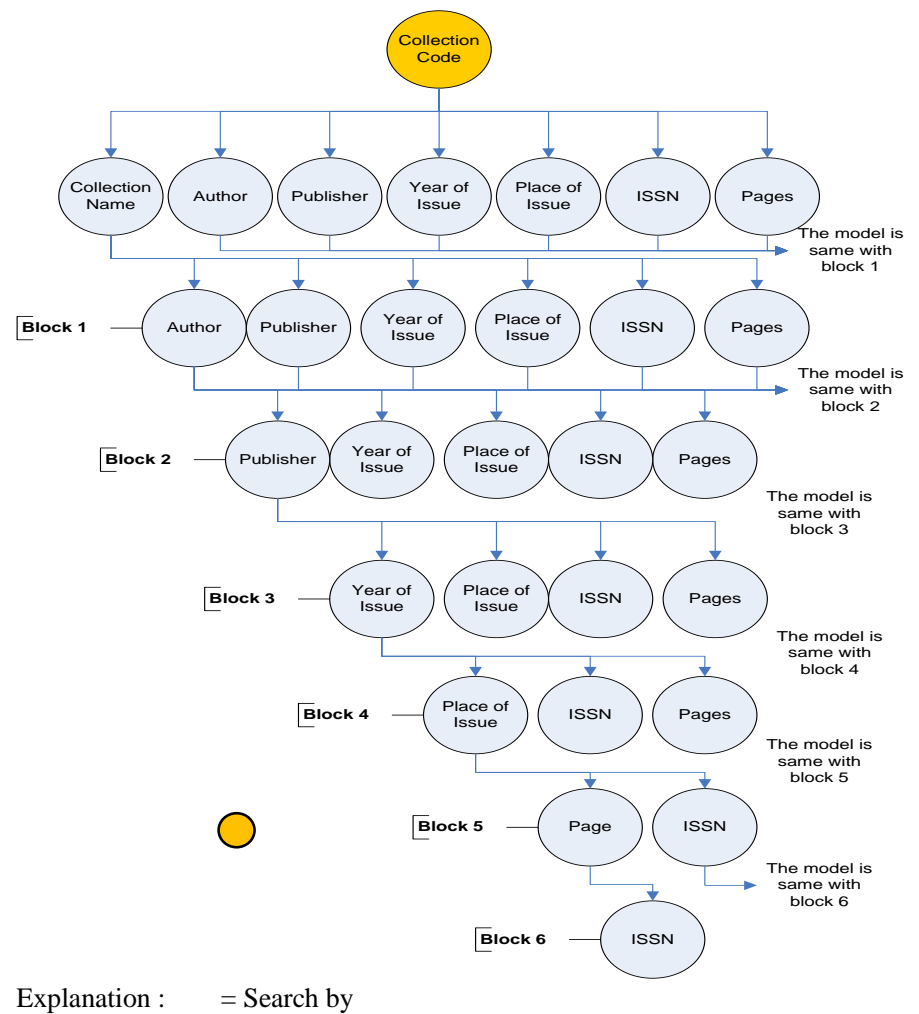

Fig. 4. Forward Chaining Concept in Digital Library Based of Expert System

3) Shows backward chaining concept in digital library based of expert system

Application of backward chaining method in a digital library can be explained by the following chart:

For example : search by ISSN 


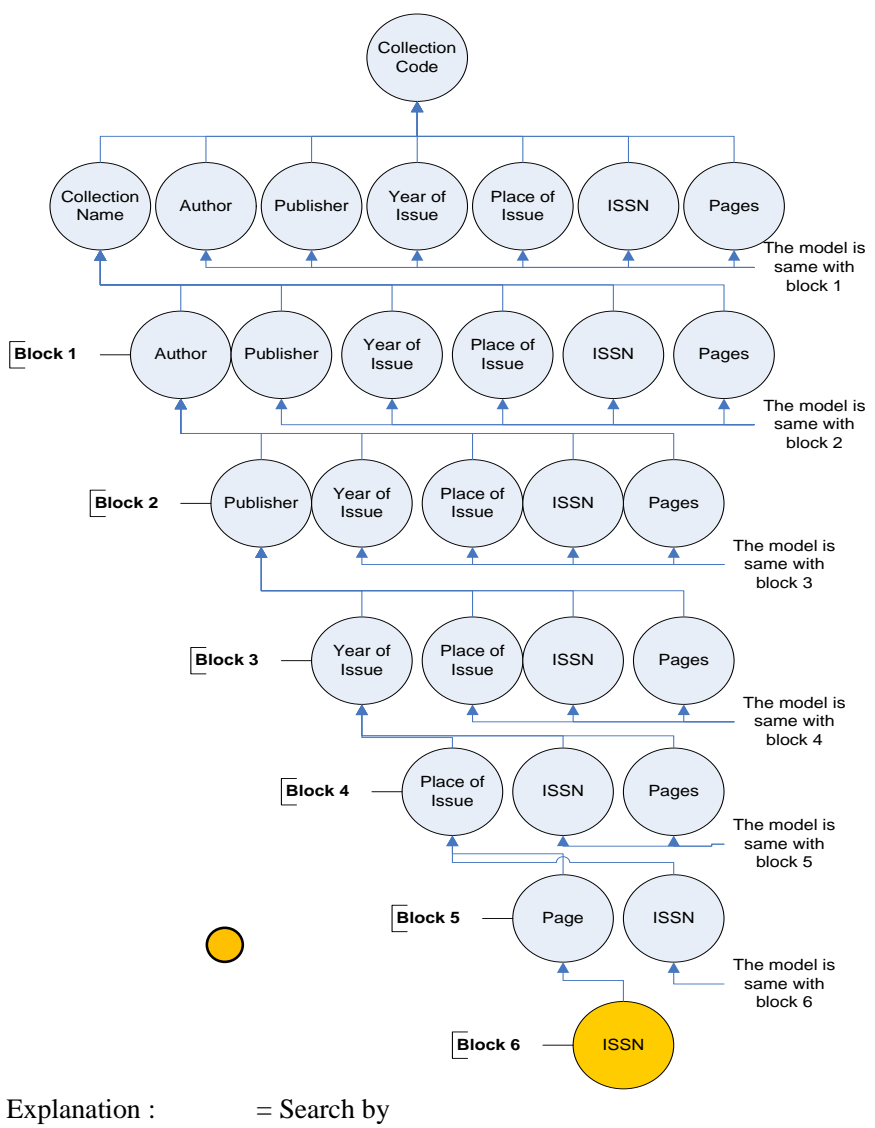

Fig. 5. Backward Chaining Concept in Digital Library Based of Expert System

4) Trials forward chaining and backward chaining performed by respondents

Respondents who did this trial was a expert and 19 staff at Indonesia Technology University conducted the field trials. The trial results are shown in table II.

Based on the table results of trials forward chaining and backward chaining performed by respondents mentioned above, it can be analyzed that the forward chaining and backward chaining method has been run in accordance with the rule of expert system inference engine.

To view the forward chaining and backward chaining method has been run in accordance with the rules can be seen in the percentage diagram of rules conformance testing.

TABLE II. TRIALS FORWARD CHAINING AND BACKWARD CHAINING METHOD

\begin{tabular}{|c|c|c|c|c|c|c|c|c|c|c|}
\hline \multirow[b]{2}{*}{ Respondent } & \multirow[b]{2}{*}{ Method } & \multicolumn{8}{|c|}{ Properties/Identity } & \multirow[b]{2}{*}{$\%$} \\
\hline & & $\begin{array}{l}\mathbf{C} \\
\mathbf{C}\end{array}$ & $\begin{array}{l}\mathbf{C} \\
\mathbf{N}\end{array}$ & $\begin{array}{l}\mathbf{A} \\
\mathbf{T}\end{array}$ & $\begin{array}{l}\mathbf{P} \\
\mathbf{L}\end{array}$ & $\begin{array}{l}\mathbf{Y} \\
\mathbf{I}\end{array}$ & $\begin{array}{l}\mathbf{P} \\
\mathbf{G}\end{array}$ & $\begin{array}{l}\mathbf{P} \\
\mathbf{I}\end{array}$ & $\begin{array}{l}\text { I } \\
\text { S }\end{array}$ & \\
\hline \multirow{2}{*}{ RS.01 } & $\mathrm{FC}$ & $\sqrt{ }$ & $\sqrt{ }$ & $\sqrt{ }$ & $\sqrt{ }$ & $\sqrt{ }$ & $\sqrt{ }$ & $\sqrt{ }$ & $\sqrt{ }$ & 100 \\
\hline & $\mathrm{BC}$ & $\sqrt{ }$ & $\sqrt{ }$ & $\sqrt{ }$ & $\sqrt{ }$ & $\sqrt{ }$ & $\sqrt{ }$ & $\sqrt{ }$ & $\sqrt{ }$ & 100 \\
\hline \multirow{2}{*}{ RS.02 } & $\mathrm{FC}$ & $\sqrt{ }$ & $\sqrt{ }$ & $\sqrt{ }$ & $\sqrt{ }$ & $\sqrt{ }$ & $\sqrt{ }$ & $\sqrt{ }$ & $\sqrt{ }$ & 100 \\
\hline & $\mathrm{BC}$ & $\sqrt{ }$ & $\sqrt{ }$ & $\sqrt{ }$ & $\sqrt{ }$ & $\sqrt{ }$ & $\sqrt{ }$ & $\sqrt{ }$ & $\sqrt{ }$ & 100 \\
\hline \multirow{2}{*}{ RS.03 } & $\mathrm{FC}$ & $\sqrt{ }$ & $\sqrt{ }$ & $\sqrt{ }$ & $\sqrt{ }$ & $\sqrt{ }$ & $\sqrt{ }$ & $\sqrt{ }$ & $\sqrt{ }$ & 100 \\
\hline & $\mathrm{BC}$ & $\sqrt{ }$ & $\sqrt{ }$ & $\sqrt{ }$ & $\sqrt{ }$ & $\sqrt{ }$ & $\sqrt{ }$ & $\sqrt{ }$ & $\sqrt{ }$ & 100 \\
\hline \multirow{2}{*}{ RS.04 } & FC & $\sqrt{ }$ & $\sqrt{ }$ & $\sqrt{ }$ & $\sqrt{ }$ & $\sqrt{ }$ & $\sqrt{ }$ & $\sqrt{ }$ & $\sqrt{ }$ & 100 \\
\hline & $\mathrm{BC}$ & $\sqrt{ }$ & $\sqrt{ }$ & $\sqrt{ }$ & $\sqrt{ }$ & $\sqrt{ }$ & $\sqrt{ }$ & $\sqrt{ }$ & $\sqrt{ }$ & 100 \\
\hline \multirow{2}{*}{ RS.05 } & FC & $\sqrt{ }$ & $\sqrt{ }$ & $\sqrt{ }$ & $\sqrt{ }$ & $\sqrt{ }$ & $\sqrt{ }$ & $\sqrt{ }$ & $\sqrt{ }$ & 100 \\
\hline & $\mathrm{BC}$ & $\sqrt{ }$ & $\sqrt{ }$ & $\sqrt{ }$ & $\sqrt{ }$ & $\sqrt{ }$ & $\sqrt{ }$ & $\sqrt{ }$ & $\sqrt{ }$ & 100 \\
\hline \multirow{2}{*}{ RS.06 } & $\mathrm{FC}$ & $\sqrt{ }$ & $\sqrt{ }$ & $\sqrt{ }$ & $\sqrt{ }$ & $\sqrt{ }$ & $\sqrt{ }$ & $\sqrt{ }$ & $\sqrt{ }$ & 100 \\
\hline & $\mathrm{BC}$ & $\sqrt{ }$ & $\sqrt{ }$ & $\sqrt{ }$ & $\sqrt{ }$ & $\sqrt{ }$ & $\sqrt{ }$ & $\sqrt{ }$ & $\sqrt{ }$ & 100 \\
\hline \multirow{2}{*}{ RS.07 } & $\mathrm{FC}$ & $\sqrt{ }$ & $\sqrt{ }$ & $\sqrt{ }$ & $\sqrt{ }$ & $\sqrt{ }$ & $\sqrt{ }$ & $\sqrt{ }$ & $\sqrt{ }$ & 100 \\
\hline & $\mathrm{BC}$ & $\sqrt{ }$ & $\sqrt{ }$ & $\sqrt{ }$ & $\sqrt{ }$ & $\sqrt{ }$ & $\sqrt{ }$ & $\sqrt{ }$ & $\sqrt{ }$ & 100 \\
\hline \multirow{2}{*}{ RS.08 } & $\mathrm{FC}$ & $\sqrt{ }$ & $\sqrt{ }$ & $\sqrt{ }$ & $\sqrt{ }$ & $\sqrt{ }$ & $\sqrt{ }$ & $\sqrt{ }$ & $\sqrt{ }$ & 100 \\
\hline & $\mathrm{BC}$ & $\sqrt{ }$ & $\sqrt{ }$ & $\sqrt{ }$ & $\sqrt{ }$ & $\sqrt{ }$ & $\sqrt{ }$ & $\sqrt{ }$ & $\sqrt{ }$ & 100 \\
\hline \multirow{2}{*}{ RS.10 } & $\mathrm{FC}$ & $\sqrt{ }$ & $\sqrt{ }$ & $\sqrt{ }$ & $\sqrt{ }$ & $\sqrt{ }$ & $\sqrt{ }$ & $\sqrt{ }$ & $\sqrt{ }$ & 100 \\
\hline & $\mathrm{BC}$ & $\sqrt{ }$ & $\sqrt{ }$ & $\sqrt{ }$ & $\sqrt{ }$ & $\sqrt{ }$ & $\sqrt{ }$ & $\sqrt{ }$ & $\sqrt{ }$ & 100 \\
\hline \multirow{2}{*}{ RS.11 } & $\mathrm{FC}$ & $\sqrt{ }$ & $\sqrt{ }$ & $\sqrt{ }$ & $\sqrt{ }$ & $\sqrt{ }$ & $\sqrt{ }$ & $\sqrt{ }$ & $\sqrt{ }$ & 100 \\
\hline & $\mathrm{BC}$ & $\sqrt{ }$ & $\sqrt{ }$ & $\sqrt{ }$ & $\sqrt{ }$ & $\sqrt{ }$ & $\sqrt{ }$ & $\sqrt{ }$ & $\sqrt{ }$ & 100 \\
\hline \multirow{2}{*}{ RS.12 } & $\mathrm{FC}$ & $\sqrt{ }$ & $\sqrt{ }$ & $\sqrt{ }$ & $\sqrt{ }$ & $\sqrt{ }$ & $\sqrt{ }$ & $\sqrt{ }$ & $\sqrt{ }$ & 100 \\
\hline & $\mathrm{BC}$ & $\sqrt{ }$ & $\sqrt{ }$ & $\sqrt{ }$ & $\sqrt{ }$ & $\sqrt{ }$ & $\sqrt{ }$ & $\sqrt{ }$ & $\sqrt{ }$ & 100 \\
\hline \multirow{2}{*}{ RS.13 } & $\mathrm{FC}$ & $\sqrt{ }$ & $\sqrt{ }$ & $\sqrt{ }$ & $\sqrt{ }$ & $\sqrt{ }$ & $\sqrt{ }$ & $\sqrt{ }$ & $\sqrt{ }$ & 100 \\
\hline & $\mathrm{BC}$ & $\sqrt{ }$ & $\sqrt{ }$ & $\sqrt{ }$ & $\sqrt{ }$ & $\sqrt{ }$ & $\sqrt{ }$ & $\sqrt{ }$ & $\sqrt{ }$ & 100 \\
\hline \multirow{2}{*}{ RS.14 } & FC & $\sqrt{ }$ & $\sqrt{ }$ & $\sqrt{ }$ & $\sqrt{ }$ & $\sqrt{ }$ & $\sqrt{ }$ & $\sqrt{ }$ & $\sqrt{ }$ & 100 \\
\hline & $\mathrm{BC}$ & $\sqrt{ }$ & $\sqrt{ }$ & $\sqrt{ }$ & $\sqrt{ }$ & $\sqrt{ }$ & $\sqrt{ }$ & $\sqrt{ }$ & $\sqrt{ }$ & 100 \\
\hline \multirow{2}{*}{ RS. 15} & $\mathrm{FC}$ & $\sqrt{ }$ & $\sqrt{ }$ & $\sqrt{ }$ & $\sqrt{ }$ & $\sqrt{ }$ & $\sqrt{ }$ & $\sqrt{ }$ & $\sqrt{ }$ & 100 \\
\hline & $\mathrm{BC}$ & $\sqrt{ }$ & $\sqrt{ }$ & $\sqrt{ }$ & $\sqrt{ }$ & $\sqrt{ }$ & $\sqrt{ }$ & $\sqrt{ }$ & $\sqrt{ }$ & 100 \\
\hline \multirow{2}{*}{ RS.16 } & $\mathrm{FC}$ & $\sqrt{ }$ & $\sqrt{ }$ & $\sqrt{ }$ & $\sqrt{ }$ & $\sqrt{ }$ & $\sqrt{ }$ & $\sqrt{ }$ & $\sqrt{ }$ & 100 \\
\hline & $\mathrm{BC}$ & $\sqrt{ }$ & $\sqrt{ }$ & $\sqrt{ }$ & $\sqrt{ }$ & $\sqrt{ }$ & $\sqrt{ }$ & $\sqrt{ }$ & $\sqrt{ }$ & 100 \\
\hline \multirow{2}{*}{ RS.17 } & FC & $\sqrt{ }$ & $\sqrt{ }$ & $\sqrt{ }$ & $\sqrt{ }$ & $\sqrt{ }$ & $\sqrt{ }$ & $\sqrt{ }$ & $\sqrt{ }$ & 100 \\
\hline & $\mathrm{BC}$ & $\sqrt{ }$ & $\sqrt{ }$ & $\sqrt{ }$ & $\sqrt{ }$ & $\sqrt{ }$ & $\sqrt{ }$ & $\sqrt{ }$ & $\sqrt{ }$ & 100 \\
\hline \multirow{2}{*}{ RS.18 } & $\mathrm{FC}$ & $\sqrt{ }$ & $\sqrt{ }$ & $\sqrt{ }$ & $\sqrt{ }$ & $\sqrt{ }$ & $\sqrt{ }$ & $\sqrt{ }$ & $\sqrt{ }$ & 100 \\
\hline & $\mathrm{BC}$ & $\sqrt{ }$ & $\sqrt{ }$ & $\sqrt{ }$ & $\sqrt{ }$ & $\sqrt{ }$ & $\sqrt{ }$ & $\sqrt{ }$ & $\sqrt{ }$ & 100 \\
\hline \multirow{2}{*}{ RS.19 } & FC & $\sqrt{ }$ & $\sqrt{ }$ & $\sqrt{ }$ & $\sqrt{ }$ & $\sqrt{ }$ & $\sqrt{ }$ & $\sqrt{ }$ & $\sqrt{ }$ & 100 \\
\hline & $\mathrm{BC}$ & $\sqrt{ }$ & $\sqrt{ }$ & $\sqrt{ }$ & $\sqrt{ }$ & $\sqrt{ }$ & $\sqrt{ }$ & $\sqrt{ }$ & $\sqrt{ }$ & 100 \\
\hline \multirow{2}{*}{ RS.20 } & $\mathrm{FC}$ & $\sqrt{ }$ & $\sqrt{ }$ & $\sqrt{ }$ & $\sqrt{ }$ & $\sqrt{ }$ & $\sqrt{ }$ & $\sqrt{ }$ & $\sqrt{ }$ & 100 \\
\hline & $\mathrm{BC}$ & $\sqrt{ }$ & $\sqrt{ }$ & $\sqrt{ }$ & $\sqrt{ }$ & $\sqrt{ }$ & $\sqrt{ }$ & $\sqrt{ }$ & $\sqrt{ }$ & 100 \\
\hline
\end{tabular}

Explanation :

FC : Forward Chaining

CC : Collection Code

AT : Author

YI : Year of Issue

PI : Place of Issue

As for the form of percentage diagram of rules conformance testing given by the respondents can be described as follows: 


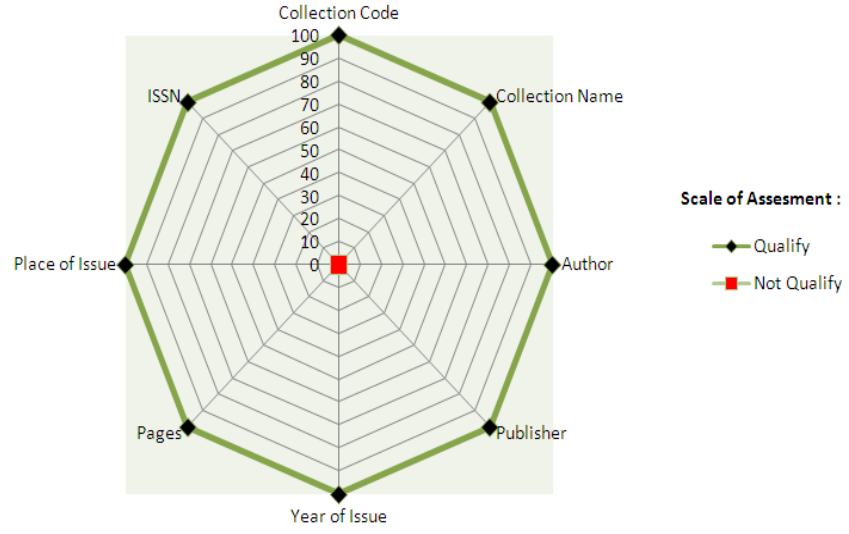

Fig. 6. Answer Percentage Diagram of Rules Conformance Testing

Based on the diagram above, it can be seen that the results of testing the suitability of digital library based of expert system rules is an outline already looks qualify. This is evidenced by the answer percentage of collection code, collection name, author, publisher, year of issue, pages, place of issue and ISSN according to the rules of backward chaining and forward chaining in the field of testing and each get a percentage of $100 \%$. System

5) Implementation of Digital Library Based of Expert

\section{a) Main Menu Page}

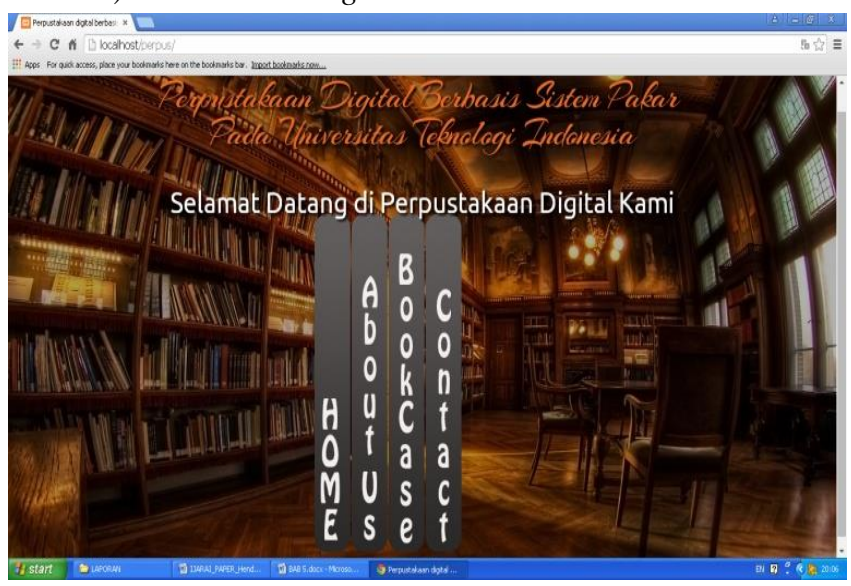

Fig. 7. Main Page

This main menu page used as link to home menu, about us menu, book case menu, and contact menu.

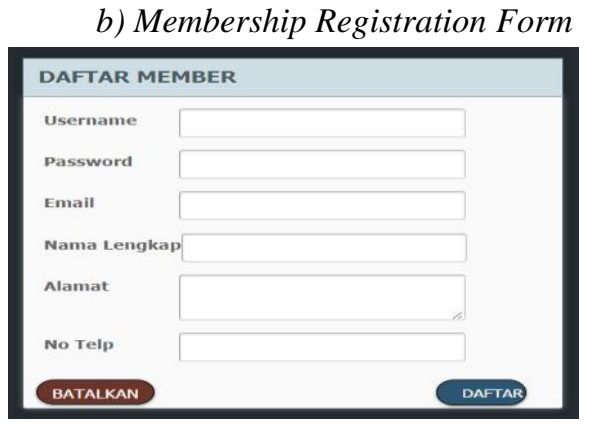

Fig. 8. Membership Registration Form
This form is used by users who will register to become a member, that all fields must be filled in accordance with the user's identity, and then click the register button to register and click cancel button to cancel the registration.

c) Member Login Form

\begin{tabular}{|l|l|}
\hline LOGIN MEMBER \\
Username \\
Password \\
BATALKAN & \\
\hline
\end{tabular}

Fig. 9. Member Login Form

This form contains the username and password for the members, so that members can search and download a collection of all the collections that exist in digital library based of expert system at Indonesia Technology University.

\section{d) Latest Collection Menu Page}

After login, the user will go to the latest collection menu, the menu contains the latest collections of Digital Library based of expert system. The following figure is a latest collection menu display.

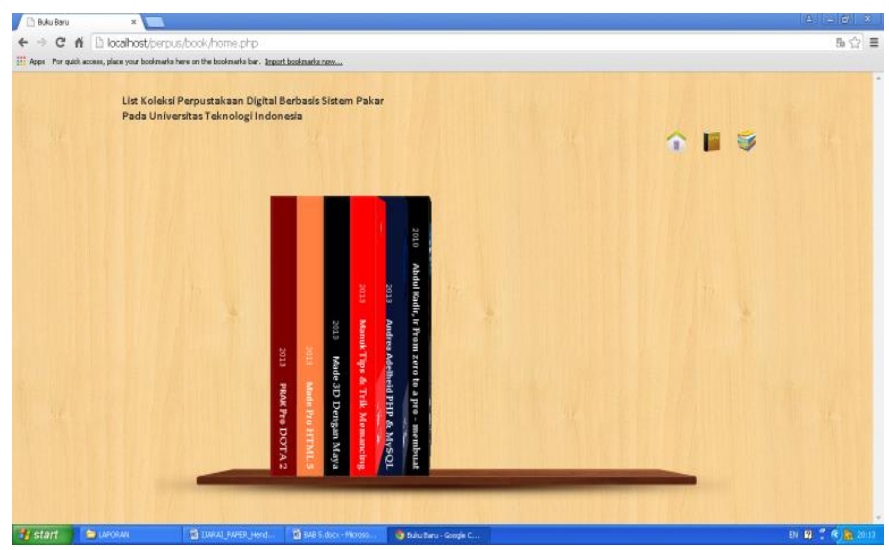

Fig. 10. Latest Collection Menu Page

e) Collection List Page

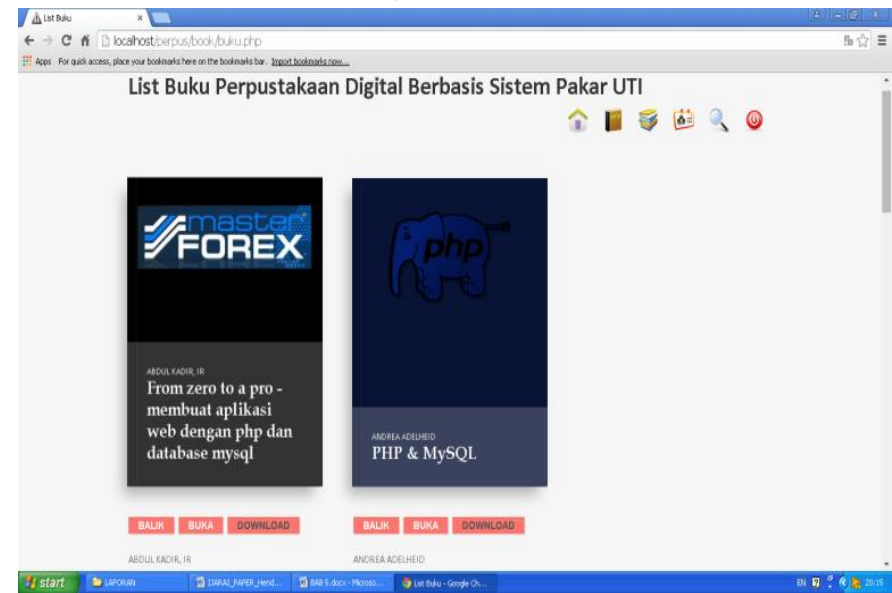

Fig. 11. Collection List Page 
This collection list page is a page that is used to display a list of collections that exist in the digital library based of expert system at Indonesia Technology University and displays the complete details of the collection identity.

\section{f) Collection Search Page}

This form contains the search facilities of data on existing collections in digital library based of expert system using a keyword based input the desired category.

\begin{tabular}{l} 
Cari Buku: \\
\begin{tabular}{|l|}
\hline bisnis \\
Berdasarkan: \\
\hline Kategori Cari \\
\hline Judul \\
Pengarang \\
\hline Kategori
\end{tabular} \\
\hline
\end{tabular}

Fig. 12. Collection Search Page

\section{g) Collection Search Result Page}

Collection Search Result Page is the page serves to display the collection search result page. The following figure is a collection search results page display.

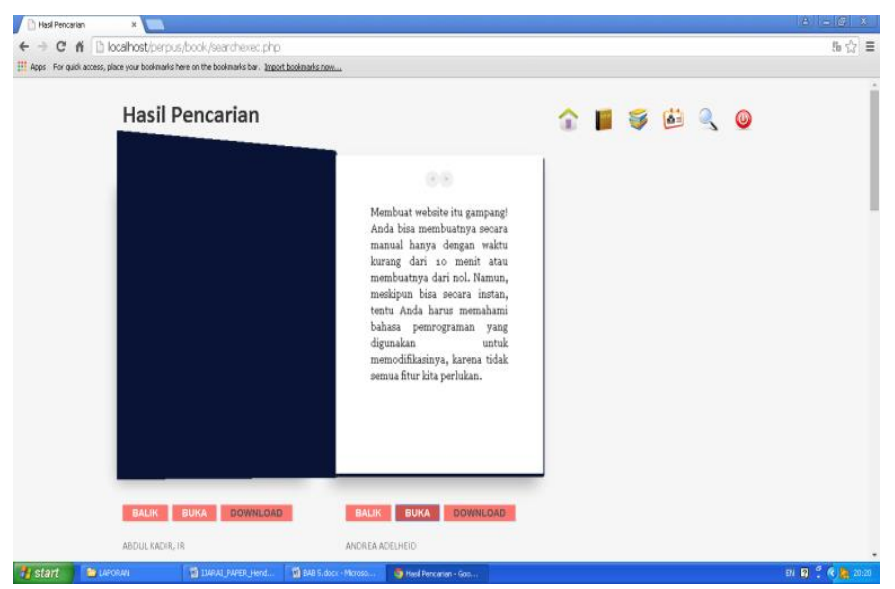

Fig. 13. Collection Search Result Page

h) Administrator Login Form

\begin{tabular}{l} 
LOGIN ADMINISTRATOR \\
Username \\
Password \\
\hline BATALKAN LOGIN \\
\hline
\end{tabular}

Fig. 14. Administrator Login Form

This form contains the username and password for the Admin, click on login button if you want to login and click cancel button if you want to cancel.

\section{i) Administrator Page}

Administrator page is a page that is used by administrators to system perform processing, such as processing of knowledge base and put the rule into an expert system inference engine. The following figure is a administrator page display.

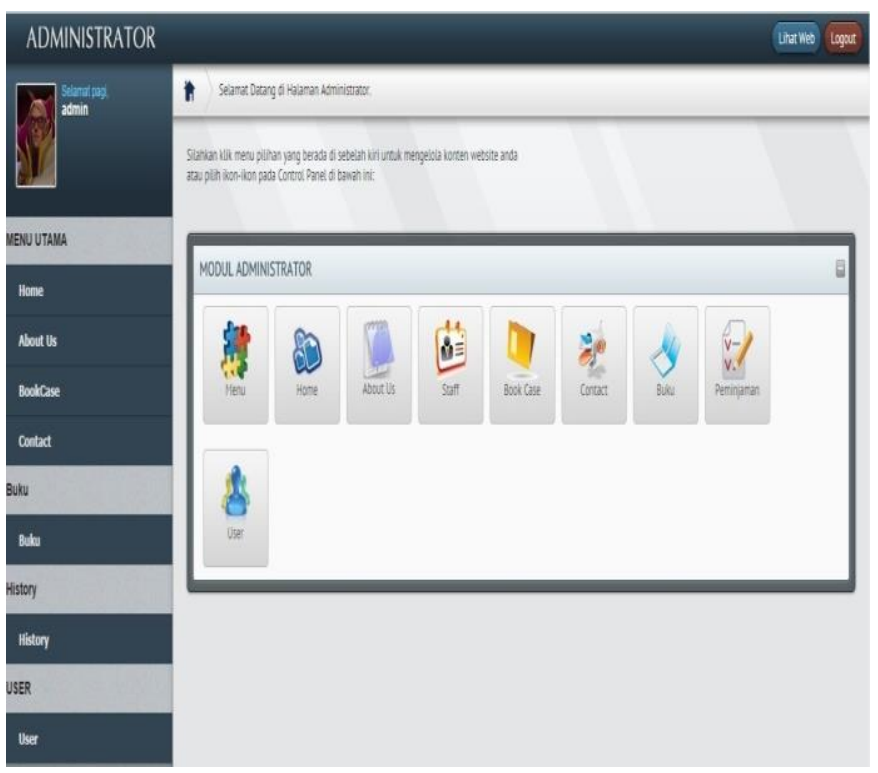

Fig. 15. Administrator Page

\section{CONCLUSIONS}

Based on the analysis that has been made and the results of the discussion in the previous section, then some conclusions can be drawn as follows:

a) With this digital library based of expert system can help the performance of existing conventional systems towards a computerized system, so as to speed up service.

b) With digital library based of expert system makes it easy for users to search the collection (books, journals, magazines, and articles) in digital form through the facilities of the internet without having to come directly to the campus library.

c) With the digital library digital library based of expert system, the concept of a real expert system can already be applied and useful in solving the existing problems in human life, especially in the field of library.

d) By looking at the optimal use of knowledge base and also the use of forward chaining and backward chaining inference engine implemented as in this digital library based of expert system, it can also be the accuracy result of the system is working at $100 \%$.

\section{ACKNOWLEDGMENT}

The authors express their gratefulness to staff at Indonesia Technology University for inspiring words and allowing them to use the examination data. They generously thank Mr. Dayung, President of Indonesia Technology University, and Mr. Ketut Semadi, Dean of Computer Faculty, Indonesia Technology University.

\section{REFERENCES}

[1] E.Bermès, and L.Fauduet, "The Human Face of Digital Preservation: Organizational and Staff Challenges, and Initiatives at the Bibliothèque 
nationale de France," in The International Journal of Digital Curation vol.6, 2011,pp.226-237.

[2] D.I.Greenstein, Thorin, and S. Elizabeth. The Digital Library: A Biography. Washington: Digital Library Federation, 2002.

[3] N. Fuhr, G. Tsakonas, T. Aalberg, M.Agosti, P. Hansen, and S. Kapidakis, "Evaluation of digital libraries," in International Journal on Digital Libraries vol. 8, 2007, pp.21-38.

[4] K. Towolawi, and Oluwakemi, "School Library Media Specialist's Awareness and Perception of Digital Library Services: A Survey," in Ozean Journal of Social Sciences vol. 6, 2013, pp.77-89.

[5] Y.A. Nada, "Construction of Powerful Online Search Expert System Based on Semantic Web," in International Journal of Advanced Computer Science and Applications vol.4, 2013, pp.181-187.

[6] Y. Qu, F. Tao, and H. Qui, “A Fuzzy Expert System Framework Using Object Oriented Techniques," in IEEE Pacific-Asia Workshop on Computational Intelligence and Industrial Application, 2008, pp. 474477.

[7] Y. Erdani, "Developing Recursive Forward Chaining Method in Ternary Grid Expert Systems," in International Journal of Computer Science and Network Security, vol.11, No.8, 2011, pp.126-130.

[8] J.C. Giarratano, and G. Riley, Expert Systems : Principles and Programming $4^{\text {th }}$ Edition. USA : PWS Publishing Co, 2004.

[9] A. A. Hopgood, Intelligent Systems for Engineers and Scientists $\left(2^{\text {nd }}\right.$ Edition). USA : CRC Press, 2001.

[10] E. Turban, and J. E. Aronson, Decision Support Systems and Intelligent System. NJ, USA: Prentice-Hall Inc, 2001.

[11] H. Divayana, "Development of Duck Diseases Expert System with Applying Alliance Method at Bali Provincial Livestock Office," in International Journal of Advanced Computer Science and Applications, Vol. 5, No. 8, 2014,pp.48-54.

[12] RC Chakraborty, 2010. Knowledge Representation: AI Course Lecture 15-22.Retrieved December, 2012, from www.myreaders.info/ html/aritificial_intelligence.html

[13] S.Kusumadewi, Artificial Intelligence (Technique and Application) $1^{\text {st }}$ Edition. Yogyakarta : Graha Ilmu, 2003.
[14] K. Donna, A Comparison of Forward and Backward Chaining Algorithms For use in a Technical Support Expert System Used for Diagnosing Computer Virus Issues. Chico : Computer Science Department California State University, 2009.

[15] T. Sharma, et.al., "Study of Difference Between Forward and Backward Reasoning," in International Journal of Emerging Technology and Advanced Engineering, vol. 2 No. 10, 2012, pp.271-273.

[16] H. Divayana, et.al., Digital Library Based of Expert System at Indonesia Technology University. Bali : Indonesia Technology University, 2015.

\section{AUTHORS PROFILE}

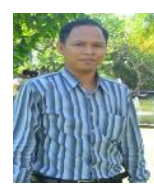

Dewa Gede Hendra Divayana, S.Kom., M.Kom., M.M., Ph.D. was born in Denpasar, Bali, in 1984. He received his Ph.D. in Information Technology from Corllins University, USA. He worked as Lecturer of Expert System, Chair of Information Technology Department, Faculty of Computer, Indonesia Technology University, Bali, Indonesia.

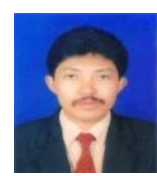

Drs. I Putu Wisna Ariawan, M.Si. was born in Ulakan, May $19^{\text {th }} 1968$. He worked as Lecturer of Mathematics Education at Ganesha University of Education. And also He worked as Guest Lecturer of Graph Theory at Faculty of Computer, Indonesia Technology University, Bali, Indonesia.

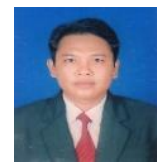

Drs. I Made Sugiarta, M.Si. was born in Badung, in 1967. He worked as Lecturer of Mathematics Education at Ganesha University of Education. And also He worked as Guest Lecturer of Dicrete Mathematic at Faculty of Computer, Indonesia Technology University, Bali, Indonesia.

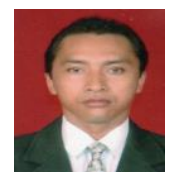

I Wayan Artanayasa, S.Pd., M.Pd. was born in Manikliyu, in 1973. He worked as Lecturer of Sport \& Health Education at Ganesha University of Education. And also He worked as Guest Lecturer of Human-Computer Interaction at Faculty of Computer, Indonesia Technology University, Bali, Indonesia. 